\title{
Metodološki problemi valorizacije tehnike alpskog skijanja
}

\author{
Dragiša N Mladenović \\ Instruktor skijanja, Škola skijanja, Kopaonik
}

\begin{abstract}
Systematic monitoring of variables relevant for success in performing alpine ski technique is necessary for detection the reserves for better sport results. Knowledge assessment of alpine ski technique, requires from examinees to perform some specific motor ski action, which composition and structure represent elements of alpine ski technique which can define level of mastering of performing basic alpine ski technique. Review the leading literature showed the differences in the grading process (from numeric to descriptive marks, from three-level to eleven-level scale), evaluation criteria, as well as the differences in the number of ski technique elements and the number of judges. Trough the literature review, selection and systemization, this paper, point out the most relevant research which are dealing with valorization of alpine ski technique.
\end{abstract}

Keywords: techniques of skiing, skiing
Sažetak: Sistematsko praćenje relevantnih varijabli uspešnosti izvođenja racionalne tehnike skijanja neophodno je radi otkrivanja rezervi za bolje sportske rezultate. Sam postupak provere znanja iz skijanja zahteva da ispitanik izvršava neku zadatu motoričku radnju na skijama, čiju strukturu i sklop predstavljaju skijaški elementi, kojim se može definisati osnovni nivo uspešnosti, ovladanosti elementima tehnike skijanja, odnosno, oni elementi tehnike koji su reprezent znanja za osnovni nivo skijanja. Pri ocenjivanju usvojenosti tehnike skijanja, pregledom literature, uočava se različitost, kako u proceni usvojenosti elemenata tehnike skijanja (od numeričkih do deskriptivnih ocena, od trostepene od jedanaestostepene skale), kako kriterijuma za ocenjivanje, tako i izbora elemenata tehnike koji se procenjuju i njihovog broja, kao i različitosti u pogledu broja ocenjivača. Pregledom dostupne literature, selekcijom i sistematizacijom prikupljene građe u ovom radu, izdvojena su relevantna istraživanja koja su se bavila valorizacijom i ocenom skijaške tehnike.

Ključne reči: tehnika skijanja, skijanje

Rad je primljen 10.05.2016.

Odobren 12.05.2016.

Kontakt podaci:

Dragiša Mladenović

Škola skijanja Kopaonik

Zaječar, Kvamerska 6,

E-mail: skikop@gmail.com 


\section{Uvod}

Utvrđivanjem i analizom raznih parametara usvojenosti tehnike alpskog skijanja, moguće je sistematsko praćenje relevantnih varijabli uspešnosti izvođenja racionalne tehnike i otkrivanje rezervi za bolje sportske rezultate na svakom nivou i stepenu obučenosti tehnike skijanja.

Skijanje kao veština predstavlja neprirodan oblik kretanja, odnosno, motoriku veštinu koja nije biološki urođena i mora da se nauči (Ilić, 1988). Skijaško znanje se sastoji od određenih elemenata skijaške tehnike koje je potrebno analizirati. Sam postupak provere znanja iz skijanja zahteva da ispitanik izvršava neku zadatu motoričku radnju na skijama, čiju strukturu i sklop predstavljaju skijaški elementi kojim se može definisati osnovni nivo uspešnosti ovladanosti elementima tehnike skijanja, odnosno, oni elementi tehnike koji su reprezent znanja za osnovni nivo skijanja (Dopsaj, 2004).

Za utvrđivanje nivoa stečenog skijaškog znanja najbolje bi bilo, kada bi ispitanik demonstrirao sve elemente skijaške tehnike, na osnovu čega bi ekspertni tim ispitivača ocenio postignuti nivo skijaškog znanja kod svakog ispitanika. Međutim, takav postupak ocenjivanja vremenski izuzetno dugo traje, budući da se procenjuje znanje većeg broja ispitanika. U takvim slučajevima ispitivači odabiraju manji broj elemenata koji reprezentuju određenu skijašku tehniku (Cigrovski, 2007).

\section{Dosadašnja istraživanja valorizacije skijaške tehnike}

Značaj istraživanja i praćenja uspešnosti usvajanja tehnike skijanja je u identifikaciji bitnih karakteristika i sposobnosti za uspeh u alpskom skijanju. Jedan od prvih uslova na tom putu je objektivna procena usvojenosti tehnike alpskog skijanja i utvrđivanje jedinstvenih kriterijuma valorizacije.

Pregledom dostupne literature, selekcijom i sistematizacijom prikupljene građe u ovom radu, izdvojena su relevantna istraživanja koja su se bavila valorizacijom i ocenom skijaške tehnike. Poseban problem valorizacije skijaške tehnike je definisanje načina na koji će se procenjivati, odnosno, utvrditi stepen usvajanja skijaškog znanja.

Problemom ocene tehnike skijanja se bavio i Dopsaj (2004), koji je sproveo istraživanje na uzorku od dvesta sedam (n=207) studenata Policijske akademije koji su pohađali obuku iz skijanja, a koji prethodno nisu imali skijaškog znanja. Obuka je realizovana pomoću deset profesora fizičke kulture, sa višegodišnjim iskustvom u izvođenju nastave i obuke skijanja. Svi profesori su prošli unifikaciju programa obuke skijanja $\mathrm{u}$ trajanju od dvanaest sati. Nakon dvanaestodnevne obuke izvršena je procena nivoa obučenosti znanja skijanja. Studenti su imali zadatak da na stazi srednjeg stepena težine demonstriraju zadati element tehnike skijanja u dužini od oko $100 \mathrm{~m}$. Ispitanik ima zadatak da pokaže tri osnovne tehnike skijanja i to kretanje u poziciji kosog spusta, plužni i paralelni zaokret, koji su izvođeni u kontinuitetu sa promenom pravca kretanja sukcesivno u obe strane. Studenti su ocenjivani tehnikom numeričkog skaliranja ocenama od pet do deset (Bakovljev, 1977), a procena je vršena na osnovu ličnog stava mentora. Ocena uspešnosti izvođenja ispitnog zadatka data je metodom ekspertske procene od tročlane komisije upotrebom iste tehnike, odnosno, svaki član komisije na osnovu ličnog stava je dao svoju ocenu. Finalnu ocenu je predstavljao prosek ocena svih članova komisije zaokruživanjem na bližu vrednost celom broju. Konačna ocena je dobijena kao prosek zbira prve dve ocene (mentora i komisije) zaokruživanjem na bližu vrednost celom broju. Da bi utvrdio koji bi ekspertski metod u cilju ocenjivanja osnovnog skijaškog znanja bio najprihvatljiviji Dopsaj (2004) je uradio validaciju tri različita ekspertska metoda: metod mentorskog ocenjivanja, metod ocenjivanja od strane ekspertske komisije i metod koji je sublimirao prva dva metoda, odnosno, sumarna prosečna ocena mentora i ekspertske komisije, kao integralna mera procene. Sa aspekta potencijalne ocene mentor je najbolje upoznat sa nivoom ovladanosti veštine skijanja svakog pojedinca, ali i potencijalno najsubjektivniji. Neutralni ispitivač ili ispitna komisija može predstavljati objektivniji metod za procenu znanja, ali postoji i verovatnoća da tokom ispitne vožnje student ne bude u stanju da realno prikaže nivo ovladanosti veštinom skijanja. Pedagoški posmatrano, svaka ocena dobijena pomenutim metodama u sebi sadrži veći ili manji deo objektivne i subjektivne informacije o nivou ovladanosti veštine skijanja. Pouzdanost procene nivoa savladanosti osnovnog znanja iz skijanja u funkciji različitih ekspertskih metoda vršena je primenom faktorske analize. Rezultati Dopsajevog (2004) istraživanja su pokazali da su sva tri metoda na generalnom nivou pedagoški prihvatljiva, ali da je treća metoda, odnosno, sumarna prosečna ocena mentora i ekspertske komisije najprihvatljivija.

Cigrovski (2007) je za procenu naučenih skijaških znanja, nakon obuke od sedam dana, kod studenata Kineziološkog fakulteta Sveučilišta u 
Zagrebu, koji nisu prethodno znali da skijaju, odabrao pet elemenata skijaške tehnike: spust koso, zaokret ka padini, osnovni zaokret, osnovno vijuganje, paralelni zaokret od padine. Elementi spust koso i zaokret ka padini demonstrirani su i ocenjeni u levu i u desnu stranu, a ukupna ocena bila je njihova aritmetička sredina. Odabrane elemente tehnike alpskog skijanja ocenjivalo je pet edukovanih ocenjivača, skijaških eksperata sa dugogodišnjim iskustvom u procenjivanju znanja alpskog skijanja. Pet ocenjivača dalo je ocenu svakom ispitaniku za demonstraciju pet odabranih elemenata skijaške tehnike. Procena usvojenog nivoa skijaškog znanja kod ispitanika valorizovana je ocenom od jedan do pet. Svaki navedeni element prikazan je i ocenjen na osnovu kriterijuma koji definišu ocenu od jedan do pet. Nakon proverenog znanja izračunata je konačna ocena za svakog ispitanika na pojedinom elementu skijaške tehnike. Proces ocenjivanja se odvijao simultano za sve učesnike. Ispitivači su prethodno bili upoznati sa kriterijumima ocenjivanja i međusobno nezavisni prilikom postupka ocenjivanja, čime se povećala tačnost procene znanja alpskog skijanja od strane ispitivača.

Panajotis (Panagiotis, 2006) i autori su istraživali korišćenje multimedia, kao instrumenta u procesu učenja alpskog skijanja. Istraživanje je sprovedeno kod trideset i dva $(n=32)$ studenta Fakulteta fizičke kulture (Department of Physical Education and Sport Science, Democritus University of Thrace, Greece), bez prethodnog iskustva $\mathrm{u}$ alpskom skijanju. Nakon pet dana obuke za ocenu su korišćena dva testa: skijaška tehnika koja je ocenjivana na jedanaestostepenoj skali od strane tri sertifikovana trenera skijanja iz Grčke federacije skijanja (Hellenic Ski Federation) i test izvođenja, čiju je ocenu činilo prosečno vreme iz dve trke veleslaloma sa deset kapija. Rezultati su pokazali da su studenti u kontrolnoj grupi koja je imala tradicionalni program učenja tehnike skijanja ostvarili prosečnu ocenu od $6.81(\mathrm{SD} \pm 1.05)$, dok su studenti koji su učili tehniku skijanja putem multimedija ostvarili prosečnu ocenu od $8.69(\mathrm{SD} \pm 1.7)$. Studenti koji su učili tehniku skijanja putem multimedija imali su i značajno bolje prosečno vreme u izvođenju veleslaloma od $48.2 \mathrm{~s}(\mathrm{SD} \pm 7.45)$, u odnosu na studente kontrolne grupe kod kojih je ovo vreme iznosilo $63.8 \mathrm{~s}(\mathrm{SD} \pm 1.88)$. Rezultati istraživanja Panajotisa ukazuju da su ispitanici koji su tehniku skijanja usvajali putem multimedija postigli bolje rezultate $\mathrm{u}$ odnosu na ispitanike koji su tehniku usvajali tradicionalnom metodom, odnosno, bez korišćenja multimedija, stoga bi pri obučavanju osnovne tehnike skijanja i kod dece skijaša početnika, značajno bilo implementirati ovaj metod. Takođe, i u ovom istraživanju u cilju provere usvojenosti tehnike skijanja korišćen je metod ekspertske procene, od strane tri ocenjivača, koji su nakon petodnevne obuke ocenjivali demonstraciju elemenata tehnike na jedanaestostepenoj skali ocene.

Blejksli (Blakeslee, 2009) ispitivač PSIA (Professional Ski Instructors of America) i raniji član PSIA Nacionalnog alpskog demo tima (National Alpine Demo Team), navodi neke važne elemente za ocenu skijaške tehnike:

- Skijaški stav: Da li su kukovi, kolena, skočni zglobovi opušteni, ali spremni za pregibanje i opružanje?

- Ravnoteža: Da li je pravac pokreta prema željenoj putanji? Da li kukovi ili glava/ramena odstupaju?

- Korišćenje skija: Da li se skije kroz zaokret kreću na rubnicima ili nehotice bivaju potisnute $u$ stranu? Prvo kroz zaokret prolaze vrhovi skija, a zadnji krajevi prate njihovu putanju.

- Interakcija skija i snega: Da li se obe skije mogu okrenuti u bilo koji potreban položaj? Da li mogu otklizavati postrance kad se traži? Da li mogu da zaustave otkizavanje i ponovo krenu napred? Da li obe skije mogu napraviti jasan trag u snegu?

- Aktivne noge nasuprot relativno stabilnom gornjem delu tela.

Novozelandsko udruženje instruktora zimskih sportova - NZSIA (New Zealand Snowsports Instructors Alliance) za 2009. godinu za licencu instruktora skijanja trećeg nivoa tokom trodnevnog ispita testira kandidate $\mathrm{u}$ tri područja: demonstraciju, slobodno skijanje i obučavanje. Kandidat mora da prođe sva tri elementa u sve tri oblasti. Minimalan broj bodova za svaki elemenat je šest od ukupno deset. Demonstracija obuhvata: paralelno skijanje, brzo vijuganje, terensku vožnju, a kandidat se procenjuje na osnovu sposobnosti demonstracije potrebne za dati nivo. Slobodno skijanje obuhvata: slobodnu vožnju, terensku vožnju i zadatke, a kandidati se procenjuju na osnovu njihove prilagodljivosti i svestranosti. Rangiranje je od 1-10, pri čemu su prolazne ocene od 6-10. Pri proceni usvojenosti tehnike skijanja, takođe i kod instruktora skijanja, kao i kod skijaša početnika se procenjuje usvojenost na osnovu ocenivanja demonstracije elemenata, čiji broj nije veliki (tri elementa tehnike) i gde su kriterijumi definisani na skali ocena $(0$ - 10).

Kanadski alpski ski tim K2 - NCO (National Capital Outaouais) je za selekciju juniorskog ski tima za 2009/2010. godinu, među skijašima 
uzrasta trinaest $\mathrm{i}$ četrnaest godina postavio kao kriterijum rang listu, pri čemu je određenim brojem bodova ocenjena demonstracija sposobnosti i tehnike skijanja. Ocenjivane su sledeće skijaške veštine: tajming i koordinacija, povezivanje faza u zaokretu, adaptacija na uslove na terenu, stav i ravnoteža, skijaški stav (prednji, zadnji, bočni), raspon pokreta nogu tokom zaokreta, prilagođavanje na teren, stabilnost gornjeg dela tela, ritam i tempo, kontrola radijusa, vođenje skije na rubnicima. Prilikom dodele bodova NCO treneri su posmatrali skijaše $\mathrm{u}$ takmičarskim uslovima u slalomu i veleslalomu. Skijaši su morali ostvariti minimum od $60 \%$, kako bi bili razmatrani za ulazak u tim i ako $60 \%$ ne garantuje mesto $u$ timu. Sagledavanjem kriterijuma za ocenjivanje K2-NCO, pri selekciji mladih skijaša takmičara $\mathrm{u}$ alpskom skijanju, može se uočiti da pojedini elementi za procenu skijaša takmičara (tipična pozicija - stav, kontrola kretanja skija, raspon položaja skija tokom zaokreta, vođenje skija na rubnicima, koordinacija, ritam, itd) se koriste i za procenu osnovne tehnike alpskog skijanja kod skijaša početnika, kako dece, tako i odraslih.

Nacionalna ski patrola u Sjedinjenim Američkim Državama - NSPC (National Ski Patrol In a Central Division, 2009), pri ocenjivanju izvođenja skijaških znanja, zahteva prelazne ocene iz sledećih alpskih veština: zaokret sa dugim, srednjim i kratkim radijusom i terensku vožnju. Konačna ocena je položio ili nije položio. Skala ocena za izvođenje svakog elementa pojedine veštine je trostepena:

- premašuje zadatak $(+)$,

- ispunjava zadatak $(=)$,

- ne ispunjava zadatak (-).

Ocenjivane su sledeće veštine:

- zaokret sa srednjim radijusom izvodi se na težem glatkom terenu;

- zaokret sa kratkim radijusom - izvodi se na težem/najtežem ravnom terenu i težem/najtežem terenu sa hupserima;

- zaokret sa dugim radijusom - izvodi se na težem ravnom terenu.

Pri ocenjivanju sa posebnom pažnjom se posmatra da li kandidat demonstrira lak, gladak i usklađen zaokret, koristeći geometriju skija i skijašku tehniku. Kod zaokreta sa kratkim radijusom ocenjuje se i nežno upijanje hupsera. Ukupan skor za zaokret sa srednjim, kratkim i dugim radijusom: položio ili nije položio. Terenska vožnja - pri ocenjivanju terenske vožnje ocenjuje se da li kandidat pokazuje kontrolisanu i usklađenu tehniku skijanja? Ukupan skor za terensku vožnju: položio ili nije položio.

$\mathrm{Na}$ fakultetu za zdravlje i sport Hedmark Univerziteta u Norveškoj (2009), praktični ispit iz oblasti skijanja za studente se ocenjuje na šestostepenoj deskriptivnoj skali od A (najviša ocena) do F (najniža ocena) i sa $\mathrm{E}$ kao minimalnom prelaznom ocenom. Studenti su procenjivani na osnovu sposobnosti demonstracije potrebne za dati nivo.

Mladenović (2015) je nakon šestodnevene obuke dece skijaša početnika procenu uspešnosti izvođenja elemenata tehnike (prelazna pozicija, međusobni odnos skija, mehanizam promene pravca kretanja, međusobna koordinacija pokreta), izvršio kroz zadatke: zaustavljanje u „plugu“, zaokret ka padini, vijuganje oko postavljenih markacija. Ocenjivanje izvođenja svakog zadatka je sprovedeno prema kriterijumu za ocenjivanje, na skali ocena od 1-5 i izvršeno je po principu ekspertske ocene tri nezavisna ocenjivača.

Istraživanje i praćenje uspešnosti usvajanja tehnike alpskog skijanja i analiza prikupljenih podataka mogu doprineti pronalaženju optimalnog odnosa i otkrivanju zakonitosti odnosa koji definišu uspeh u alpskom skijanju.

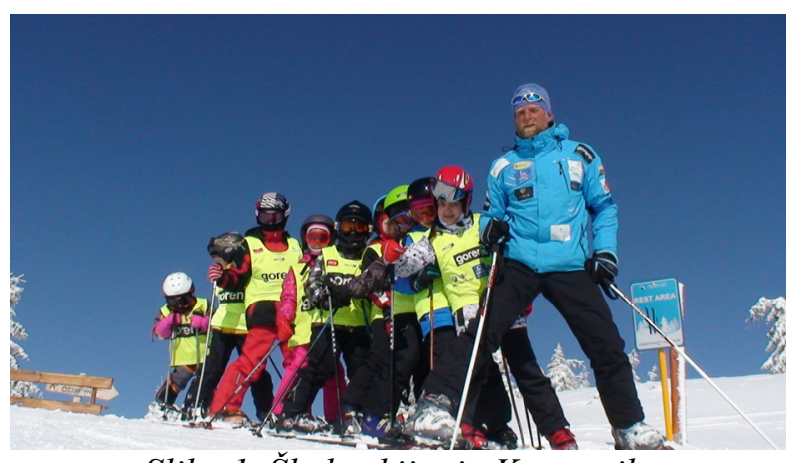

Slika 1. Škola skijanja Kopaonik 


\section{Zaključak}

Objektivna procena usvojenosti tehnike alpskog skijanja neophodna je radi utvrđivanja različitih uticaja (morfoloških, motoričkih, funkcionalnih, psiholoških, socijalnih, itd) na usvajenje osnovne tehnike skijanja i identifikaciju bitnih karakteristika i sposobnosti koji definišu uspeh u usvajanju tehnike alpskog skijanja. Za razliku od takmičara, gde je kriterijumska varijabla vreme ostvareno na takmičarskoj stazi ili mesto na rang listi, pri ocenjivanju usvojenosti elemenata tehnike alpskog skijanja, pregledom literature, uočava se različitost, kako u proceni usvojenosti elemenata tehnike skijanja (od numeričkih do deskriptivnih ocena, od trostepene od jedanaestostepene skale), kriterijuma za ocenjivanje, tako i izbora elemenata tehnike koji se procenjuju i njihovog broja, kao i različitosti u pogledu broja ocenjivača (metod mentorskog ocenjivanja, metod ocenjivanja od strane ekspertske komisije, itd). Stoga bi pravac budućih istraživanja trebalo da bude usmeren na dalje praćenje, preciziranje i ujednačavanje kriterijuma valorizacije i otkrivanje rezervi za bolje sportske rezultate na svakom nivou i stepenu obučenosti tehnike alpskog skijanja. 


\section{Literatura}

1. Bakovljev (1977). Osnovi metodologije pedagoških istraživanja. Naučna knjiga, Beograd.

2. Blakeslee M. (2009). Prepare for Superficial Inconsistencies. The Official Publication of the Professional Ski Instructors of America - Eastern / Education Foundation. S mreže skinuto 12.10.2009. s: www.psia-e.org

3. Cigrovski V. (2007). Učinkovitost različitih metoda u procesu učenja skijaških znanja. Doktorska disertacija. Zagreb, Hrvatska: Kineziološki fakultet.

4. Dopsaj M., Jocić D., Blagojević M., Vučković G. (2004). Validacija različitih ekspertskih metoda za procenu osnovnog znanja skijanja kod studenata policiske akademije. Bezbednost, 46(2):289-300.

5. Ilić B. (1988). Smučanje. NIPRO, „Partizan“, Beograd.

6. Hedmark universiti College, Faculty of Sports and Health (2009). International semeter in Physical Education Out - door acitivities in winter and springs. S mreže skinuto 12.10.2009.s:

7. New Zealand Snowsports Instructors Alliance, Ski Level Three Course Outline 2009. /on line/. Sa mreže skinuto 08.10.2009. s: www.nzsia.net

8. NCO Alpine Ski Team K2, Team Selection Policy 2009/2010. /on line/. Sa mreže skinuto 08.10.2009. s: www.ncoski.com

9. Panagiotis A., Elias M., Apostolos S., Euagelos T. (2008). Multimedia: an instructional tool in the teaching process of alpine ski. Department of Physical Education and Sport Science, Democritus University of Thrace, Greece.

10. Mladenović D. (2015). Usvajanje osnovne tehnike alpskog skijanja kod dece uztasta 5-8 godina. Doktorska disertacija. Beograd, Srbija: Univerzitet u Beogradu, Fakultet sporta i fizičkog vaspitanja Beograd. 